\title{
LA CERÁMICA "TIPO KUASS": AVANCE A LA SISTEMATIZACIÓN DEL TALLER GADITANO ${ }^{1}$
}

\author{
THE KUASS TYPE POTTERY. ADVANCE TO THE \\ SISTEMATISATION OF THE CÁDIZ WORKSHOP
}

\author{
por \\ ANA M $M^{a}$ NIVEAU DE VILLEDARY Y MARIÑAS ${ }^{2}$
}

RESUMEN A fines de la década de los sesenta el investigador francés Michel Ponsich publica los resultados preliminares de sus excavaciones en el yacimiento norteafricano de Kuass (Arcila, Marruecos), y llama la atención sobre una serie de vasos que recuerdan las producciones campanienses, aunque con una serie de particularidades que le llevan a proponer que se trata de imitaciones de fabricación local. Desde ese momento este tipo de cerámica es conocida bajo el apelativo de "cerámica de Kuass" aunque la posterior investigación ha podido determinar el origen gaditano de la producción y definir este nuevo taller mediterráneo.

ABSTRACT At the end of the seventies, the French researcher Michel Ponsich published the preliminary results of his excavations in the north-african settlement of Kuass (Arcila, Morocco). He put emphasis on a set of glasses which are reminiscent of Campanien productions. Nevertheless, such glasses peculiarities led him to suggest that he was dealing with locally manufactured imitations. From that moment on, this type of ceramics is known under the name of "Kuass ceramics", although later investigations determined the origin of the production from Cadiz and defined this new Mediterranean workshop.

\section{INTRODUCCIÓN.}

La investigación sobre las producciones de barniz negro ha avanzado de forma espectacular desde que Nino Lamboglia (1952) propusiera una nueva tipología para la cerámica campaniense en 1950. A este primer intento de sistematización de las campanienses universales se han ido añadiendo numerosos estudios

1. Este trabajo, que se enmarca en nuestra Tesis Doctoral, dirigida por el Dr. D. Ruiz Mata y titulada: "Las cerámicas rojas de tradición griega (fines s. IV-s. II a.n.e.) en la bahía gaditana: Tipología y significado económico y político", fue presentado en su primera versión al III Congreso de Arqueología Peninsular, celebrado en Vila Real (Portugal) en septiembre de 1999. Ahora presentamos, corregidas y ampliadas, algunas de las conclusiones preliminares a las que hemos llegado en el transcurso de la investigación.

2. Área de Prehistoria. Universidad de Cádiz. Avda. Gómez Ulla s/n. 11003 , Cádiz. 
puntuales sobre producciones concretas (Amo 1970; Cura y Principal 1994; Morel 1969, 1982 y 1986; Pedroni 1986 y 1990; Principal 1998; Py 1978; Sanmartí 1978 a y b; Solier 1969; Solier y Sanmartí 1978, etc.) y algunas obras de síntesis (Adroher y López Marcos 1995 y 1996; Barberá 1970; Morel 1980 y 1981; Pérez Ballester 1986; Sparkes y Talcott 1970) que poco a poco han ido aclarando el complicado mundo del barniz negro, -técnica vigente desde el s. $V$ a.n.e. y que pervive hasta el cambio de era-, y trazando el mapa de los diferentes talleres mediterráneos que estuvieron en funcionamiento a lo largo de estos siglos.

A grandes rasgos y aún a riesgo de simplificar la cuestión podemos diferenciar tres grandes momentos en la producción y difusión del barniz negro en el Mediterráneo. En un primer momento la técnica, de origen griego, sería exclusiva de los talleres atenienses. A lo largo de estos primeros momentos se van imponiendo unas formas determinadas y sobre todo un estilo, que pronto alcanza un éxito hasta entonces no conseguido por ninguna otra producción. La vajilla griega ampliamente comercializada, se convierte, funcional o simbólicamente, en elemento de lujo indispensable para las poblaciones indígenas de los lugares donde llega. La demanda aumenta conforme avanza el s. IV a.n.e., de manera que los talleres se multiplican y ya en esta época en las ciudades de la Magna Grecia documentamos una creciente actividad artesanal (Morel 1978: 164). En un determinado momento, y por causas diversas (Descat 1987), la cerámica ática deja de llegar a los mercados occidentales ${ }^{3}$. Sin embargo, durante estos dos siglos la estética helenística había calado hondo creando una especie de koine estilística y formal. Es a partir de este momento cuando empiezan a surgir una serie de talleres locales, de difusión más restringida (Morel 1980: 88), que con su producción cubren la demanda de vajillas barnizadas en sus respectivas zonas. Este segundo momento abarca prácticamente todo el siglo III a.n.e. Aunque la investigación no se pone de acuerdo, nosotros siguiendo a algunos colegas (Adroher y López Marcos 1995: 24), hemos optado por llamar "protocampanienses" a esta serie de talleres, cuyo periodo de apogeo se sitúa a caballo entre la llegada de las últimas vajillas áticas y la difusión masiva de las primeras campanienses universales, que podemos situar entre finales del s. III y comienzos del II a.n.e. Con la progresiva hegemonía de Roma se inaugura una nueva época caracterizada por la industrialización de la producción y la monopolización del mercado por las producciones campanienses A, B y en menor medida la C(Morel 1980: 100-101), que provoca la progresiva desaparición de los talleres locales que no pueden competir con las vajillas romanas (Adroher y López Marcos 1996: 12).

A nosotros nos interesa este segundo período, que es donde, cronológica y culturalmente, debemos situar la producción de cerámica de tipo "Kuass". Como demuestran los últimos trabajos sobre la difusión de la cerámica griega en la Península, ésta llega de forma masiva a las poblaciones fenicias del sur peninsular (Cabrera 1997, Cabrera y Perdigones 1996), donde lejos de desempeñar como entre las poblaciones ibéricas un papel simbólico y de prestigio, la vajilla tiene un uso cotidiano y funcional (Cabrera 1997: 382). Las formas documentadas, su presencia en contextos de habitación y la rápida amortización de las piezas así lo demuestran. No debe pues extrañarnos, que una zona profundamente semitizada e inmersa de lleno en los circuitos comerciales mediterráneos como es la gaditana (Cabrera 1994), participara así mismo de esa koiné estética helénica a la que hemos aludido. Recientes trabajos (Cabrera 1997) empiezan a revelar un panorama en el que la cerámica ática y en particular la barnizada se constituye en un elemento presente con relativa frecuencia en los conjuntos cerámicos de la zona. Una vez que la vajilla ática comienza a escasear a finales del s. IV, la población gaditana cuenta con la suficiente capacidad técnica y el grado de demanda necesario como para comenzar una producción propia, primero con ciertos titubeos pero que se impone de forma espectacular en la siguiente centuria.

3. Aunque tradicionalmente se pensaba que la cerámica griega dejaba de llegar a nuestras costas a raíz de la aplicación de los tratados comerciales entre Cartago y Roma, hoy en día se tienden a valorar otra serie de factores, de índole productiva, y se admite que la causa principal del cese del comercio es la crisis agrícola de la ciudad de Atenas, que no termina de recuperarse tras los desastres de la Guerra del Peloponeso (Rostovtzeff 1967: 88 ; Adroher y López Marcos 1995: 12). 


\section{LA VAJILLA DE “TIPO KUASS" O LA PRODUCCIÓN GADITANA DE CERÁMICA "PROTOCAMPANIENSE".}

Estamos hablando de vajilla gaditana y sin embargo en la bibliografía especializada estas producciones son consideradas norteafricanas: ¿en qué nos basamos para afirmar que en realidad se trata de una producción centrada en Cádiz?. Partimos de la premisa de que se trataría de la vajilla común a toda el área del Círculo del Estrecho (Tarradell 1960), es decir al espacio geopolítico gaditano (Millán 1998), por lo tanto, los ejemplares de Kuass, tanto si se trata de importaciones como si fueron fabricados en el complejo industrial marroquí, lo que por ahora no queda claro, quedarían incluidos en la producción del nuevo taller que intentamos definir.

\subsection{La distribución de la vajilla.}

La distribución de la producción de tipo "Kuass" es el principal argumento que podemos esgrimir para la defensa del origen gaditano del taller (Niveau de Villedary 1998: 24). Si analizamos los lugares en los cuales encontramos esta vajilla ${ }^{4}, \mathrm{y}$ teniendo en cuenta tanto el número de ejemplares que aparecen como las formas documentadas y los contextos en los que la hallamos, podemos trazar una serie de círculos concéntricos, imaginarios, a partir del centro neurálgico que debe situarse en torno a la bahía gaditana.

En el yacimiento fenicio del Castillo de Doña Blanca (El Puerto de Santa María, Cádiz), por ahora el único gran núcleo de habitación que se ha podido definir en el entorno de la bahía de Cádiz (Ruiz Mata 1999), la presencia de esta cerámica es frecuente y común en la última etapa del yacimiento centrada en el s. III a.n.e. y que termina coincidiendo con los episodios bélicos de la Segunda Guerra Púnica (Ruiz Mata y Pérez 1995: 75-76). Tanto en el propio yacimiento (Ruiz Mata y Pérez 1995: 74-75) como en el vecino poblado de Las Cumbres (Niveau de Villedary y Ruiz Mata e.p.), los vasos de tipo "Kuass" no sólo no se nos presentan como elementos puntuales y de lujo sino que parecen constituir la vajilla propia del momento, pues morfológica y tipológicamente cubren prácticamente todas las funciones del servicio de mesa y de iluminación y puntualmente otras de carácter suntuario (Niveau de Villedary e.p.). En el solar ocupado por la actual ciudad de Cádiz (Muñoz 1995-96) hasta el momento sólo se han podido definir estructuras de carácter funerario y cultual de lo que podemos inferir la funcionalidad suntuaria del espacio. La presencia de cerámica de tipo "Kuass" es muy frecuente también en estos contextos. Por el carácter sacro de los contextos en los que se hallan, tumbas y pozos rituales (Muñoz 1989; Ventura 1990; Blanco 1998;

\footnotetext{
4. Agradecemos desde estas líneas a todos los colegas que nos han permitido acceder a materiales aún inéditos, a información de sus trabajos o nos han facilitado el acceso a los fondos de los Museos; su colaboración y amabilidad, en especial a E. Sanmartí del Museo de Catalunya, J. Barberá, X. Aquilué, J. Tremoleda, P. Castanyer y M. Santos del Conjunto Arqueológico de Empúries, J. Principal de la Universidad de Barcelona, P. Cabrera del Museo Arqueológico Nacional, H. Bonet del S.I.P. de la Diputación de Valencia, M. Olcina del Museo Arqueológico de Alicante, I. Grau de la Universidad de Alicante, E. Ruiz Valderas y M. Martín Camino del Museo Arqueológico de Cartagena, J.M. y C. García Cano del Museo Arqueológico de Murcia, V. Page del Museo Monográfico del Cigarralejo (Mula, Murcia), J.L. López Castro de la Universidad de Almería, A.M. Adroher de la Universidad de Granada, K. Mansel del Instituto Arqueológico Alemán, M. Belén, J.J. Ventura y E. Ferrer de la Universidad de Sevilla, A.M. Arruda de la Universidad de Lisboa, R. González y F. Barrionuevo del Museo Municipal de Jerez de la Frontera, A. Sáez y D. Moreno del Museo Municipal de San Fernando, M. Bendala, L. Roldán y J. Blánquez de la Universidad Autónoma de Madrid, F. Gómez y O. Guerrero de la Universidad de Huelva, M. Kbiri Alaoui del Parque Arqueológico de Chellah (Rabat, Marruecos), J.A. Ruiz Gil, L. Lagóstena e I. Pérez de la Universidad de Cádiz, F. Blanco, P. Pineda, F.J. Sibón, I. Córdoba y J.M. Gener arqueólogos que han excavado la necrópolis gaditana. Y muy especialmente a D. Ruiz Mata director de las excavaciones del Castillo de Doña Blanca.
} 
Pineda y Miranda 1999), los vasos que documentamos son los de mayor calidad técnica y estilística (Niveau de Villedary 1999). Todo el entorno de la bahía, en esta época se halla jalonado de una serie de pequeños enclaves de carácter industrial, dedicados a la pesca y a la transformación industrial de estos productos. Documentamos factorías de salazones en la ciudad de Cádiz (Muñoz, Frutos y Berriatúa 1988; Frutos y Muñoz 1996) y en toda la costa atlántica desde El Puerto de Santa María hasta Rota (Ruiz Gil 1986 y 1991 ; Ruiz Gil y Ruiz Fernández 1987). También en estos núcleos industriales la vajilla de "Kuass" era de uso habitual entre sus habitantes (Ruiz Gil 1991: 1212), dato más para afirmar que no se trata de una vajilla de lujo de carácter restringido. Por último y dentro todavía del entorno de la bahía gaditana, ha sido posible documentar la producción de esta cerámica en los alfares púnicos de Torre Alta, situados en el casco urbano de la ciudad de San Fernando (Frutos y Muñoz 1994: 398). Algo más alejado del centro consumidor y productor que creemos se puede situar en la bahía de Cádiz, la vajilla de tipo "Kuass" es aún muy frecuente en toda la campiña de la provincia de Cádiz (Niveau de Villedary e.p.)-Mesas de Asta, poblado ${ }^{5}$ y necrópolis (González, Barrionuevo y Aguilar 1997: lám. 3 y 4), Cerro Naranja (González 1985: 95) y demás villas rústicas ${ }^{6}$ etc-, marismas -poblado de Ébora (Carriazo 1970: 71) y santuario de la Algaida (Ferrer 1995: 481), ambos en el término Municipal de Sanlúcar de Barrameda-, bahía de Algeciras -Carteia (Bendala y otros 1994: 90 y 93) y santuario de Gorham's Cave (Belén y Pérez e.p.)-. En un siguiente círculo incluimos los yacimientos onubenses -Tiñosa (Belén y Fernández-Miranda 1978), cabezos de Huelva (Rufete 1996), Niebla (Belén y Escacena 1990)-, del bajo Guadalquivir-Itálica (Luzón 1978), Sevilla (Vera 1990), Cerro Macareno (Pellicer, Escacena y Bendala 1983)-, sur de Portugal (Arruda 1997: 139) -Mértola, Castro Marim, Faro, Cerro da Rocha Branca e incluso las documentamos en Miróbriga- y norte de África (López Pardo 1990) -Kuass (Ponsich 1968 y 69), Zilil (Akerraz y otros 1981-82: 204), Lixus (Ponsich 1981: Pl. XXVII), Sidi Abdselam del Behar (López Pardo 1990: 39), Kudia Tebmain (Tarradell 1960: 83) y Melilla (Gozálbes 1987: 107)-. Todavía compartiendo los rasgos que los definen en cierta manera como pertenecientes al área del Círculo del Estrecho, esta cerámica la volvemos a encontrar, junto al resto de elementos de tipología gaditana en los enclaves púnicos de la costa de Málaga -El Torreón (Soto 1988: 5), Cerro de la Tortuga (López Malax-Echevarría 1973), Málaka (Gran-Aymerich 1991), Morro de Mezquitilla (Martín Ruiz 1995: 126)-y de forma más puntual en los de Granada-Almuñécar (Pascual 1971-72: 333) y Salobreña (Arteaga y otros 1992)-y Almería-Adra (Adroher y López Marcos 1989: 382), Ciavieja (Carrilero y López Castro 1994: 259), Cabecico de Parra (López Castro y otros 1987-88: 169) y Villaricos, necrópolis (Rodero y otros 1996: 381) y ciudad ${ }^{7}$-. Aunque aún no podemos fijar estos límites con precisión, a grandes rasgos observamos como en todas las áreas que hemos enumerado hasta ahora la vajilla se nos presenta completa, con todas sus formas, de lo que podemos inferir un uso funcional y habitual y no simbólico o de prestigio, independientemente del contexto en la que aparezca, de habitación, funerario, cultual, industrial etc. La no excesiva calidad técnica de las piezas, la rápida amortización de éstas y el hecho de que en algunos casos

5. Desde estas líneas agradecemos a R. González y F. Barrionuevo del Museo Arqueológico Municipal de Jerez de la Frontera, su amabilidad al habernos permitido revisar los materiales procedentes de las excavaciones de $\mathrm{M}$. Esteve en la ciudad romanoturdetana de Asta Regia. Entre el material hemos podido identificar platos de pescado y cuencos de borde reentrante, publicados por Esteve como campaniense (Esteve 1945: fig. 1 y 1950: fig. 1) y reconocidos por Ponsich como cerámica de tipo "Kuass" (Ponsich 1969: 63 y 65).

6. Gracias a las prospecciones superficiales realizadas en el marco del Proyecto de Investigación Sistemático: "Paleogeografía Humana del extremo noroccidental de Cádiz. Los procesos culturales desde el Neolítico a Época Medieval. Formas de contacto y aculturación", dirigido por R. González, directora del Museo Arqueológico Municipal de Jerez de la Frontera, tenemos conocimiento, no sólo de la existencia de estos pequeños asentamientos, sino también de la frecuente presencia en ellos de cerámicas de "tipo Kuass". De nuevo debemos agradecer (ver nota 5) a los responsables del Proyecto la información y el acceso a los materiales, aún inéditos.

7. Agradecemos a J.L. López Castro, de la Universidad de Almería, que nos haya permitido estudiar la cerámica "tipo Kuass" inédita, procedente de sus intervenciones de urgencia en lo que fue la antigua Baria (López Castro 1991: 84). 
incluso sustituyan a las formas correspondientes en cerámica común son argumentos de peso que apoyan nuestra hipótesis. Nos aventuramos entonces a afirmar que la vajilla de tipo "Kuass" se distribuye en el espacio que, en mayor o menor medida suponemos controlado por Gadir, es decir lo que se ha definido como "Círculo del Estrecho" (Niveau de Villedary 1998) y cuyos límites seguramente se hallan en el Algarve por el oeste, bajo Guadalquivir por el Norte, Lixus por el sur y costa malagueña por el este, teniendo en cuenta que los círculos culturales se solapan unos con otros por lo que tampoco podemos fijar fronteras de forma categórica (Ferrer 1998).

\subsection{El comercio gaditano y la cerámica “tipo Kuass" .}

Fuera de esta zona más o menos vinculada a Cádiz, encontramos una serie de puntos en los que se han documentado también nuestras cerámicas y que sin embargo debemos analizar desde otra óptica. No creemos que haya que insistir en la importancia y el peso del comercio dentro de la economía gaditana desde su misma fundación. Después de una primera época de economía básicamente colonial, la ciudad de Cádiz ya desvinculada de la metrópolis, participa activamente en los circuitos comerciales mediterráneos fundamentalmente con un producto: las salazones y salsas de pescado (López Castro 1995, Frutos y Muñoz 1996). Como es habitual en estos momentos entre los cargamentos de los mercantes, formados principalmente por los envases contenedores de los productos que se comercializan, hallamos otros vasos, que bien forman parte de la vajilla de uso de la tripulación o se incluyen como lotes secundarios para su venta. Sea de una forma u otra, lo cierto es que siguiendo esta pista, ha sido posible documentar la presencia de piezas (en este caso aisladas y no formando parte de la vajilla habitual) de cerámica de tipo "Kuass" fuera del área de uso estricto de ésta, frecuentemente acompañando a ánforas de tipología gaditana y como resultado del comercio de la metrópolis atlántica. Si en el caso anterior, la distribución de la vajilla de tipo "Kuass" nos había servido para delimitar más o menos, el área de influencia gaditana, ahora, la distribución de esta serie de elementos que acompañan a los productos gaditanos nos indican los principales centros con los que Gadir mantenía relaciones comerciales (Dies Cusí 1994) e incluso las rutas secundarias de redistribución de los productos. Encontramos vasos de tipo "Kuass" en Ampurias ${ }^{8}$ donde su presencia es notable. Esto nos indica la importancia de las relaciones comerciales establecidas entre las antiguas colonias griega y fenicia (Cabrera 1994), y en el resto de los principales puertos de comercio mediterráneos (Niveau de Villedary 1998) de la Península -Villaricos ${ }^{9}$, Sagunto (Blánquez 1985), La Albufereta (Bonet y Mata 1988: 18), Los Nietos (Linarejos 1990: 116)-y centromediterráneos-Ibiza (Fernández 1983: 230), Cerdeña ${ }^{10}$, Sicilia ${ }^{11}$, Cartago (Thuillier 1982: 257)-. La distribución de estos ejemplares nos informa de las rutas seguidas por los comerciantes gaditanos, principalmente la de las islas-Villaricos, Cerdeña, Sicilia y de allí posiblemente a la Magna Grecia-(López Castro 1997), sin menospreciar otras alternativas o secundarias que conducirían a Ibiza, Ampurias o Cartago, aunque somos de la opinión de que el comercio de los productos gadiritas estuvo siempre en manos gaditanas y no se realizó a través de agentes o intermediarios (Millán 1998: 96)

8. Hemos podido constatar la relativa presencia de cerámica barnizada gaditana en la antigua colonia griega en dos visitas. En nuestra primera estancia en el yacimiento en 1996, E. Sanmartí nos mostró fragmentos de vasos, que por pastas y barnices, pertenecían sin duda a nuestro taller. Durante la segunda visita a Ampurias en julio de 1999, pudimos aislar varias formas de "tipo Kuass" entre los materiales procedentes de los contextos de la segunda mitad del s. III a.n.e. de la Neápolis, bajo el templo de Esculapio y en el relleno del proteikisma de la muralla griega (Sanmartí y otros 1986).

9. Ver nota 7.

10. Piezas expuestas en el Museo de Cagliari (Información personal de C.J. Pérez).

11. Procedentes de Lilibeo (Información personal de·F. Barrionuevo). 
como a veces se ha interpretado por algunos textos (Ps.Arist., Mir., 136). Resulta también interesante la presencia de cerámicas gaditanas en importantes enclaves interiores-Baza (Conde 1992: 90), el Amarejo (Blánquez 1985), La Serreta (Olcina y otros 1998: 38)-, que jalonan, como no podía ser de otro modo, importantes vías de comunicación y rutas de comercio.

\subsection{Los hornos.}

Pero quizás el argumento de mayor peso a la hora de afirmar que nos hallamos ante la producción de un taller gaditano, sea la documentación de esta producción a esta orilla del Estrecho. En un primer momento estas cerámicas, documentadas en el yacimiento norteafricano de Kuass, al que debe el nombre, se asociaron a la producción del horno III de yacimiento (Ponsich 1968 y 1969). Sin embargo, Ponsich, en ningún momento afirma con seguridad que se fabricasen allí, ni presenta fallos de hornos o cualquier otro dato que constate la fabricación de la vajilla barnizada en los hornos de Kuass. Recientes revisiones ${ }^{12}$ parecen echar por tierra las conclusiones preliminares de Ponsich, ya que parece que esta cerámica, numéricamente poco significante por otra parte, aparece en contextos de habitación y no directamente asociada a los espacios industriales. De todas formas y aunque contemos con datos para dudar de la producción de cerámica barnizada en el yacimiento norteafricano, no podemos a priori desechar la hipótesis de que los alfares de Kuass fabricasen, posiblemente en pequeñas cantidades, esta vajilla, pues nos consta que se fabrican no sólo ánforas de tipología gaditana sino también otro tipo de vasos menores de carácter más doméstico que industrial, pero sí podemos poner en duda la capacidad del complejo industrial de Kuass para surtir a toda el área gaditana de este producto, que hemos visto de uso habitual y común (Niveau de Villedary e.p.). Posiblemente el horno de Kuass, si es que llegó en algún momento a fabricar cerámicas barnizadas, fuese uno de tantos alfares que diseminados por todo el espacio culturalmente dependiente de Gadir, fabricasen el repertorio cerámico propio del Círculo del Estrecho, que en gran medida está aún por definir.

Con posterioridad la excavación de los alfares púnicos de Torre Alta (San Fernando, Cádiz) en el entorno de la bahía gaditana (Frutos y Muñoz 1994) ha permitido documentar la producción de cerámica de tipo "Kuass" en el área donde su uso es más común y su aparición en todo tipo de contexto habitual. Al igual que los hornos de Kuass, se trata de un complejo industrial dedicado a la fabricación de envases industriales de tipología gaditana, destinados a contener las salazones. Junto a esta producción principal se ha documentado otra subsidiaria de elementos de uso doméstico, entre los que destacan por su número y calidad la vajilla barnizada de rojo. El panorama se ha ampliado recientemente, tras la excavación de otro conjunto de hornos, aún inéditos, próximos a los primeros, en la Avenida de Pery Junquera, también en el casco urbano de la ciudad de San Fernando. Curiosamente, toda la orilla oriental de la bahía, los actuales términos municipales de San Fernando y Puerto Real, se nos muestran como amplias zonas industriales y alfareras destinadas a cubrir la alta demanda de envases que el dinámico comercio gaditano requiere, a la vez que surte a la población de elementos de uso cotidiano, pues cada vez son más numerosos los conjuntos alfareros excavados, que hoy por hoy documentamos desde el s. VI a.n.e. En nuestro caso concreto sin embargo, tan sólo tenemos documentada la etapa final de la producción, ya que aún no contamos con alfares que se puedan fechar en el s. III a.n.e. Por la tipología anfórica y vascular, la producción de Torre Alta debe situarse hacia fínes del III y comienzos del II a.n.e. (García Vargas 1998), en un momento en el que la producción de vajilla fina de mesa barnizada comienza a decaer, ante la importación cada vez mayor de campaniense A. Los hornos de Pery Junquera habría que situarlos algo más allá, quizás a mediados del II (Toraya y otros e.p.),

12. Información de M. Kbiri Alaoui, que en la actualidad lleva a cabo el estudio y revisión de los materiales procedentes de las excavaciones de Ponsich en el yacimiento de Kuass. 
documentando la etapa final de nuestras producciones, ya de carácter residual. Que no contemos precisamente con hornos que evidencien la fabricación de la vajilla de "Kuass" en el momento álgido de la producción, es decir en el s. III a.n.e. o en sus comienzos a fines de la centuria anterior, no es óbice para que nos atrevamos a asegurar que se trata desde sus comienzos de la producción de un taller gaditano. Simplemente se trata de que aún no se han documentado los hornos de esos momentos, pero la tradición alfarera de San Fernando, el hecho de que sí tengamos constatada la producción en sus etapas finales y la amplia distribución de los productos en toda el área de Cádiz en contextos tempranos, creemos que son argumentos con el suficiente peso como para asegurar que nos hallamos, sin duda alguna, ante la producción de un taller "protocampaniense" del área punicizante (Morel 1978: 153), concretamente el que corresponde al Círculo del Estrecho.

\section{LA CERÁMICA DE "TIPO KUASS” O LA VAJILLA DE MESA DEL CÍRCULO DEL ESTRECHO.}

Llegado a este punto cabe hacernos otra pregunta: si la distribución de este tipo de cerámica es tan amplia y a simple vista la diversidad morfológica y sobre todo técnica de los vasos es bastante apreciable, ¿por qué nos atrevemos a asegurar que se trata de la producción planificada de un taller/grupo de talleres, y no de imitaciones aisladas y espontáneas que reproducen los perfiles helenísticos a los que la población púnica del Círculo del Estrecho se había acostumbrado?.

\subsection{Las formas.}

El análisis detallado de la vajilla, nos ha llevado a una serie de conclusiones. En primer lugar la tipología de los vasos se reduce a poco más de una docena de formas básicas (Niveau de Villedary e.p.). Los miles de ejemplares de diferentes yacimientos que hemos visto, pueden incluirse, con los lógicos subgrupos y variantes, en alguna de las diecisiete formas que hemos definido. Si dejamos aparte las formas menos frecuentes, posiblemente caprichos ocasionales del artesano, la mayoría de los vasos pertenecen a alguna de las diez formas más frecuentes de platos, platitos, bolsales, copas, cuencos, lucernas y ungüentarios que hemos podido definir. El hecho así presentado, no parece obra de la casualidad. Funcionalmente tenemos representado el servicio de la vajilla de mesa (Bats 1988: 203) prácticamente completo, con platos, vasos para beber y formas de uso polivalente. Éstos constituyen la mayor parte de los ejemplares. En menor proporción numérica pero significativamente más importantes nos encontramos con dos tipos de lucernas, que cubrirían el servicio de iluminación y con un grupo de formas cerradas y delicadas, menos frecuentes, a las que se podría otorgar un uso de tipo más bien suntuario o de tocador.

\subsection{Dimensiones.}

Una segunda lectura, basada en el estudio de las dimensiones de los vasos, nos ofrece datos aún más clarificadores a la hora de demostrar que nos hallamos ante una producción consciente, pues aunque a primera vista la diversidad de éstos parece evidente, el análisis de alturas y diámetros, nos ha permitido comprobar la regularidad de los tamaños y proporciones de las diferentes formas, hasta un grado de uniformidad muy significativo. Se trata en suma de formas canonizadas, que guardan, en general, las proporciones de los prototipos áticos en el caso de las formas más arcaicas y de los sucesivos productos del resto de talleres protocampanienses en las formas más evolucionadas. La aparente diversidad morfológica debemos atribuirla 
al hecho de que se trata de una producción de tipo artesanal ${ }^{13}$, en ningún caso industrializada como ocurrirá con las campanienses universales. Aún siguiendo unas líneas básicas, los artesanos cuentan con la suficiente libertad de ejecución en detalles de formas, inclinación de las paredes, decoración, etc...

\subsection{Características técnicas.}

Desde el punto de vista técnico, la variedad es mayor. En líneas generales, las superficies de los vasos se recubren de una especie de pigmento o barniz de tonalidad rojiza. Pero la realidad es muy diferente, pocos son los vasos que presentan un barniz rojo y uniforme. Con frecuencia un mismo vaso no presenta un color uniforme, sino que estos varían desde el rojo intenso hasta el negro pasando por toda una gama de pardos. Esta deficiente calidad técnica se explica posiblemente, porque en el fondo no se trata de una producción de lujo, sino que la vajilla "tipo Kuass" es de uso bastante común entre los habitantes de esta zona. Las piezas deterioradas se sustituirían con frecuencia, vista la envergadura de la producción y la amortización sería pues bastante rápida. La diversidad de pastas, pigmentos y esquemas decorativos podría responder también a la existencia de un indeterminado número de talleres que fabricarían estas cerámicas, que como es frecuente en esta época, se multiplican.

\subsection{Formas barnizadas y cerámica común.}

El éxito de la producción es evidente. No sólo es, como hemos tenido ocasión de demostrar, la vajilla de semilujo de uso común a toda el área del Círculo del Estrecho en esta época, sino que además hemos podido comprobar como determinadas formas llegan incluso a sustituir a sus correspondientes en cerámica común. Así en el momento en que la presencia de cerámica de tipo "Kuass" se generaliza, los platos de pescado barnizados de tipología helenística sustituyen casi por completo a los típicos platos pintados evolución de los tradicionales platos fenicios (Ruiz Mata 1987: 304). Lo mismo ocurre con las copas de borde reentrante. En los yacimientos en los que la presencia de la vajilla de tipo "Kuass" es frecuente, las formas barnizadas y con pie exento, dominan por completo a aquellas fabricadas en cerámica común, que tan frecuentes son en los yacimientos turdetanos del bajo Guadalquivir. Pero quizás el caso más obvio sea el de las lucernas. Tenemos documentadas dos tipos de lucernas barnizadas, radicalmente diferentes desde un punto de vista morfológico pero con la misma funcionalidad. Una de ellas responde al prototipo de lucerna helenística, de cuerpo globular y larga piquera cerrada (Howland 1958). La otra es mucho más curiosa pues se trata de la adaptación de formas helénicas bastante arcaicas al tradicional gusto púnico por las lucernas abiertas. En este caso hemos podido observar como estas nuevas formas sustituyen casi completamente a las tradicionales lámparas fenicias. Tenemos constancia que los llamados cuencos-lucerna (Luzón 1973: 37) no se utilizan aquí con esa funcionalidad, pues apenas si se documentan unos pocos ejemplares y los que aparecen no presentan rastros de fuego. Por tanto podemos asegurar que en esta época, las lucernas se limitan a las formas barnizadas de tipo "Kuass" con alguna excepción poco significativa que, por los complicados perfiles, se pueden interpretar como caprichos de artesano.

13. A este respecto, y aunque referidas a las producciones protocampanienses de los talleres de Rosas, resultan clarificadoras las conclusiones a las que llega J. Principal (1998: 155-157). 


\section{CONCLUSIONES.}

En un reciente trabajo de síntesis, los autores se hacían eco de la falta de información e investigación, que en referencia a este tema, había para el sur peninsular y se lamentaban del escaso interés que parecía existir por el tema (Adroher y López Marcos 1995: 39). Se intuía, que dada la importancia comercial y política de Cádiz y la cada vez mayor presencia de importaciones griegas, debía de haber habido algún tipo de taller que con mayor o menor fortuna y más o menos conscientemente, hubiese producido imitaciones que ocuparan el vacío dejado por la vajilla ática, pero no era posible ir más allá de las meras suposiciones. Sin embargo, hoy por hoy, tras el rastreo exhaustivo de los materiales, su estudio detallado y las conclusiones culturales y comerciales a las que hemos llegado, estamos en condiciones de afirmar que finalmente se ha identificado, definido y delimitado la producción de barniz negro (rojo en nuestro caso) del sur peninsular y noroccidente de África. Por tanto lo que hasta ahora conocíamos por cerámica de tipo "Kuass" es en realidad el producto de este taller gaditano "protocampaniense", que cubre la demanda de vajillas barnizadas en el área del Círculo del Estrecho desde el cese de las importaciones áticas a fines del s. IV a.n.e. hasta el momento en que se impone la Campaniense $\mathrm{A}$ a mediados del s. II a.n.e., y que conoce un extraordinario éxito entre la población local y se exporta junto al resto de productos gaditanos durante este siglo y medio.

\section{BIBLIOGRAFÍA.}

ADROHER AUROUX, A.M. y LÓPEZ MARCOS, A. (1989): "Informe del estudio de cerámicas de barniz negro en el Museo Provincial de Almería. 1989”, Anuario Arqueológico de Andalucía II: 382-389.

(1995): "Las cerámicas de barniz negro. I. Cerámicas áticas y protocampanienses", Florentia lliberritana 6: $11-53$.

(1996): "Las cerámicas de barniz negro. II. Cerámicas campanienses”, Florentia Iliberritana 7: 11-37.

AKERRAZ, A., EL KHATIB-BOUJIBAR, N., HESNARD, A., KERMOVANT, A., LENOIR, E. y LENOIR, M. (1981-82): "Fouilles de Dchar Jdid, 1977-1980" Bulletin d'Archéologie Marocaine 14: 169 - 244.

AMO DE LA HERA, M. DEL (1970): "La cerámica campaniense de importación y las imitaciones campanienses en Ibiza", Trabajos de Prehistoria 27: 201 - 256.

ARRUDA, A.M. (1997): As cerâmicas áticas do Castelo de Castro Marim, no quadro das exportaçoes gregas para a Península Ibérica. Lisboa, Ed. Colibrí, Facultad de Letras de Lisboa.

ARTEAGA, O., NAVAS, J., RAMOS, J.F. y ROOS, A.M. (1992): Excavación de urgencia en el Peñón de Salobreña (Granada). Salobreña.

BARBERÁ, J. (1970): "La cerámica campaniense”, Informació Arqueològica 2: 38 - 46.

BATS, M. (1988): Vaisselle et alimentationà Olbia de Provence (v. 350 - v. 50 av. J.-C.). Modeles culturels et catégories céramiques (Revue Archéologique de Narbonnaise suppl.18). París, Éditions du Centre National de la Recherche Scientifique.

BELÉN, M. y ESCACENA, J.L. (1990): "Niebla (Huelva). Excavaciones junto a la Puerta de Sevilla (1978 1982). La cata 8", Huelva Arqueológica XII: 167 - 305.

BELÉN, M. y FERNÁNDEZ-MIRANDA, M. (1978): "La Tiñosa (Lepe, Huelva)", Huelva Arqueológica IV: $197-287$.

BELÉN, M. y PÉREZ, I. (e.p.): "Gorham's Cave, un santuario en el Estrecho. Avance de los materiales cerámicos”, IV Congreso Internacional de Estudios Fenicios y Púnicos, Cádiz, 2-6 octubre, 1995. 
BENDALA GALÁN, M., ROLDÁN GÓMEZ, L., BLÁNQUEZ PÉREZ, J. y MARTÍNEZLLLLO, S. (1994): "Proyecto Carteia : Primeros resultados", Cuadernos de Prehistoria y Arqueología de la Universidad Autónoma de Madrid 21: 81 - 116.

BLANCO JIMÉNEZ, F.J. (1998): Memoria de las excavaciones efectuadas en el solar ubicado en la Plaza de Asdrúbal esquina con el Paseo Marítimo durante 1997/98. Memoria inédita depositada en la Delegación Provincial de Cultura de Cádiz.

BLÁNQUEZ PÉREZ, J.J. (1985): “Un nuevo material cerámico de engobe rojo”, VI Congreso Internacional de Arqueología Submarina, Cartagena, 1982: 463 - 474.

BONET, H. y MATA, C. (1988): "Imitaciones de cerámica campaniense en la Edetania y Contestania", Archivo Español de Arqueología 61: 5 - 38.

CABRERA BONET, P. (1994): "Cádiz y el comercio de productos griegos en Andalucía Occidental durante los siglos V y IV a.C.", Trabajos de Prehistoria 51, 2: 89 - 101.

- (1997): "La presencia griega en Andalucía (siglos VI al IV a.C.)", La Andalucía Ibero-Turdetana (Siglos VI - IV a. C.). Huelva, 1994 (FERNÁNDEZ JURADO, J., RUFETE TOMICO, P. y GARCÍA SANŻ, C. eds.). Huelva Arqueológica XIV: 367 - 390.

- y PERDIGONES MORENO, L. (1996): "Importaciones áticas del s. V a.C. del Cerro del Prado (Algeciras, Cádiz)", Trabajos de Prehistoria 53, 2: 157 - 165.

CARRIAZO, J. DEM. (1970): El Tesoro y las primeras excavaciones de Ébora (Excavaciones Arqueológicas en España 69). Madrid.

CARRILERO MILLÁN, M. y LÓPEZ CASTRO, J.L. (1994): “Ciavieja: un asentamiento de época púnica en el poniente almeriense", El mundo púnico. Historia, sociedad y cultura. Coloquios de Cartagena I. (Cartagena, 17-19 de novembre de 1990) (GONZÁLEZ BLANCO, A., CUNCHILLOS ILARRI, J.L. y MOLINA MARTOS, M. eds.) Murcia: 251 - 268.

CONDE BERDOS, M.J. (1992): Arte ibérico. Colección arqueológica Durán/Vall-llosera. Barcelona.

CURA-MORERA, M. y PRINCIPAL I PONCE, J. (1994): "La producció de les tres palmetes radials amb roseta central o " $3+1$ ", Cuadernos de Prehistoria y Arqueología Castellonense 16: 173 - 188.

DESCAT, R. (1987): “L'économie d'une cité grecque au IVe siècle avant J.C. : l'exemple athénien", Revue des Études Anciennes LXXXIX, 3-4: 239 - 252.

DIES CUSÍ, E. (1994): “Aspectos técnicos de las rutas comerciales fenicias en el Mediterráneo occidental (siglos IX - VII a.C.)", Archivo de Prehistoria Levantina 21: 311 - 336.

ESTEVE GUERRERO, M. (1945): Excavaciones en Asta Regia (Mesas de Asta, Jerez). Campaña 1942-43 (Acta Arqueológica Hispana III). Madrid.

(1950): Excavaciones en Asta Regia (1945-1946) (Informes y Memorias 22). Madrid.

FERNÁNDEZ, J.H. (1983): Guía del Puig des Molins. (Trabajos del Museo Arqueológico de Ibiza 10) Ibiza.

FERRER ALBELDA, E. (1995): Los púnicos en Iberia: análisis historiográfico y arqueológico de la presencia púnica en el sur de la península ibérica. Tesis Doctoral inédita. Universidad de Sevilla.

- (1998): "Suplemento al mapa paleoetnológico de la Península Ibérica: Los púnicos de Iberia", Rivista di Studi Fenici XXVI, 1: 31 - 54.

FRUTOS REYES, G. DE y MUÑOZ VICENTE, A. (1994): "Hornos púnicos de Torre Alta (San Fernando, Cádiz)", Arqueología en el entorno del Bajo Guadiana: 393 - 414.

(1996): "La industria pesquera y conservera púnico-gaditana: Balance de la investigación. Nuevas perspectivas”, Spal 5: $133-165$. 
GONZÁLEZ RODRÍGUEZ, R. (1985): "Excavaciones de urgencia en el Cerro Naranja (Jerez de la Frontera, Cádiz), 1985", Anuario Arqueológico de Andalucía 1985 III: 90 - 96.

—, BARRIONUEVOCONTRERAS, F. y AGUILAR MOYA, L. (1997): "Notas sobre el mundo funerario en la Baja Andalucía durante el período turdetano", La Andalucía Ibero-Turdetana (Siglos VI - IV a. C.). Huelva, 1994 (FERNÁNDEZ JURADO, J., RUFETE TOMICO, P. y GARCÍA SANZ, C., eds.). Huelva Arqueológica XIV: 245 - 268.

GOZÁLBEZ CRAVIOTO, E. (1987): "Economía de la ciudad antigua de Rusadir", Aldaba. Revista del Centro asociado a la U.N.E.D. de Melilla. 9: 97 - 120.

GRAN-AYMERICH, J.M.J.(1991): Malaga phénicienne et puniche. Recherches franco-espagnoles 19811988. París.

HOWLAND, R.H. (1958): Greek Lamps and their survivals (The Athenian Agora IV). Princeton.

LAMBOGLIA, N. (1952): "Per una classificazione preliminare della ceramica campana", I Congreso di Studi Liguri (1950): 139-206.

LINAREJOS CRUZ PÉREZ, M. (1990): Necrópolis ibérica de Los Nietos (Cartagena, Murcia)(Excavaciones Arqueológicas en España 158). Madrid.

LÓPEZ CASTRO, J.L. (1991): “Cartago y la Península Ibérica: ¿imperialismo o hegemonía?”, La caída de Tiro y el auge de Cartago. V Jornadas de Arqueología fenicio-púnica de Ibiza. Ibiza, 1990 (Trabajos del Museo Arqueológico de Ibiza 25): 73 - 84.

LÓPEZ CASTRO, J.L. (1995): Hispania Poena. Los fenicios en la Hispania romana. Barcelona, Crítica. - (1997): "Los fenicios occidentales y Grecia", Xaipe. II Reunión de historiadores del Mundo Griego Antiguo (Sevilla, 18-21 de diciembre de 1995). Homenaje al profesor Fernando Gascó (PRESEDO, F.J., GUINEA, P., CORTÉS, J.M. y URÍAS, R. eds.). Sevilla: 95 - 105.

— , SAN MARTÍN MONTILLA, C. y ESCORIZA MATEU, T. (1987-88): "La colonización fenicia en el estuario del Almanzora. El asentamiento de Cabecico de Parra en Almizaraque (Cuevas de Almanzora, Almería)", Cuadernos de Prehistoria de la Universidad de Granada 12 -13: 157-169.

LÓPEZ-MALAX ECHEVARRÍA, A. (1973): “Una comunicación sobre la cerámica de barniz rojo", XII Congreso Nacional de Arqueología, Jaén 1971. Zaragoza: 389 - 394.

LÓPEZ PARDO, F. (1990): "Sobre la expansión fenicio-púnica en Marruecos. Algunas precisiones a la documentación arqueológica”, Archivo Español de Arqueología, 63: 7 - 41.

LUZÓN NOGUÉ, J.M. (1973): Excavaciones en Itálica. Estratigrafía en el Pajar de Artillo (Campaña 1970) (Excavaciones Arqueológicas en España 78) Madrid, Ministerio de Educación y Ciencia.

MARTÍN RUIZ, J.A. (1995): Catálogo documental de los fenicios en Andalucía. Sevilla, Consejería de Cultura, Junta de Andalucía.

MILLÁN LEÓN, J. (1998): Gades y las navegaciones oceánicas en la Antigüedad (1000 a.C. - 500 d.C.). Écija, Ed. Gráficas Sol.

MOREL, J.-P. (1969): “Etudes de la céramique campanienne, I : L'atelier des petites estampilles", Mélanges de l'École Française de Roma LXXXI: 59-117.

-(1978): “A propos des céramiques campanienne de France et d'Espagne”, Archéologie en Languedoc 1: 149-168.

(1980): "La céramique campanienne: acquis et problemes", Céramiques hellenistiques et romaines. Centre de Recherche d'Histoire Ancienne 36: 85-122.

(1981): Céramique Campanienne: Les Formes. (Bibliothéque des Écoles Françaises d'Athenes et de Rome 244). París. 
(1982): "La céramique à vernis noir de Carthage-Byrsa: nouvelles données et éléments de comparaison", Centre d'Études et Documentation Archéologique de la Conservation de Carthage (Cartaghe Dossiers 1): 43-76. (1986): "La céramique à vernis noir de Carthage, sa diffusion, son influence", Cahiers des Études Anciennes XVIII: 26 - 55.

MUÑOZ VICENTE, A. (1989): “Excavaciones arqueológicas de urgencia en la necrópolis de Cádiz: Área de la Plaza de Asdrúbal. Sector H”, Anuario Arqueológico de Andalucía III: 87 - 97.

- (1995-96): "Secuencia histórica del asentamiento fenicio-púnico de Cádiz: Un análisis crono-espacial tras quince años de investigación arqueológica”, Boletín del Museo de Cádiz VII: 487 - 508.

— , FRUTOS REYES, G. DE y BERRIATÚA HERNÁNDEZ, N. (1988): “Contribución a los orígenes y difusión comercial de la industria pesquera y conservera gaditana a través de las recientes aportaciones de las factorías de salazones de la Bahía de Cádiz", Actas del I Congreso Internacional El Estrecho de Gibraltar. Ceuta, 1987., I. Madrid: 487 - 508.

NIVEAU DE VILLEDARY Y MARIÑAS, A.M. (1998): "El sur de la península y el norte de África durante los siglos IV y III a.C.", El Mediterráneo en la Antigüedad: Oriente y Occidente. I Congreso Español de Antiguo Oriente Próximo. Madrid, 1997 (GALÁN, J.M., CUNCHILLOS, J.-L. y ZAMORA, J.-A., eds.).

- (1999): "El pozo. Los materiales", Memoria científica de la intervención Edificio "Puerto Varela", Avda. de Andalucía s/n. Cádiz (P. PINEDA REINA y J. M. MIRANDA ARIZ, eds.) Memoria inédita depositada en la Delegación Provincial de Cultura de Cádiz.

— (e.p.): "La producción de cerámicas rojas de tradición griega en la zona de Cádiz. Las cerámicas de tipo "Kuass": Una nueva perspectiva", Madrider Mitteilungen.

— y RUIZ MATA, D. (e.p.): "El poblado de Las Cumbres (Castillo de Doña Blanca): Urbanismo y materiales del s. III a.n.e.", IV Congreso Internacional de Estudios Fenicios y Púnicos. Cádiz, 2 al 6 de octubre de 1995.

OLCINA DOMENECH, M., GRAU MIRA, I., SALA SELLÉS, F., MOLTO GISBERT, S., REIG SEGUI, C. y SEGURA MARTI, J.M. (1998): "Nuevas aportaciones a la evolución de la ciudad ibérica: el ejemplo de La Serreta", Actas del Congreso Internacional Los Iberos. Príncipes de Occidente. Estructuras de poder en la sociedad Ibérica (Barcelona, 1998): 35-46.

PASCUAL GUASCH, R. (1971-72): “Arqueología Submarina en Andalucía (Almería y Granada)”, Ampurias 33-34: 321 - 334.

PEDRONI, L. (1986): Ceramica a vernice nera da Cales. Nápoles, Liguori editore.

- (1990): Ceramica a vernice nera da Cales 2. Nápoles, Liguori editore.

PELLICER, M., ESCACENA, J.L. y BENDALA, M. (1983): El Cerro Macareno. (Excavaciones Arqueológicas en España 124). Madrid, Ministerio de Cultura.

PÉREZ BALLESTER, J. (1986): "Las cerámicas de barniz negro “campanienses": Estado de la cuestión”, Boletín del Museo Arqueológico Nacional IV: 27 - 45.

PINEDA REINA, P. y MIRANDA ARIZ, J.M (1999): Memoria científica de la intervención Edificio "Puerto Varela", Avda. de Andalucía s/n. Cádiz. Memoria inédita depositada en la Delegación Provincial de Cultura de Cádiz.

PONSICH, M. (1981): Lixus. Le quartier des temples. Rabat.

- (1968): "Alfarerías de época fenicia y púnico-mauritana en Kuass (Arcila, Marruecos)", Papeles del Laboratorio de Arqueología de Valencia 4: 3-25.

(1969): "Les céramiques d'imitation: la campanienne de Kouass. Région d'Arcila-Maroc", Archivo Español de Arqueología 42: 56-80.

PRINCIPAL-PONCE, J. (1998): Las importaciones de vajilla fina de barniz negro en la Cataluña Sur y Occidental durante el siglo III a.C. Comercio y dinámica de adquisición en las sociedades indígenas. (British Archaeological Reports. International Series 729). Oxford, Tempus Reparatum. 
PY, M. (1978): "Une production Massaliète de céramique pseudo-attique à vernis noir", Rivista di Studi Liguri XLIV, 1-4: 175 - 198.

RODERO, A., PEREA, A., CHAPA, T., PEREIRA, J., MADRIGAL, A. y PÉREZ-DIE, M.C. (1996): “La Necrópolis de Villaricos (Almería)", Homenaje a M. Fernández-Miranda (Complutum Extra 6, I): 373-383. ROSTOVTZEFF, M. (1967): Historia social y económica del mundo helenístico. I, Madrid.

RUFETE TOMICO,P.(1996): El Final de Tartessos y el mundo Ibero-turdetano de Huelva. Tesis Doctoral inédita. Universidad de Sevilla.

RUIZ GIL, J.A. (1986): "Sondeos Arqueológicos de urgencia para la delimitación de las factorías de salazones púnico-gaditanas de El Puerto de Santa María, Cádiz", Anuario Arqueológico de Andalucía III: 101-105.

- (1991): "Cronología de las factorías de salazones púnicas de Cádiz", Atti del ll Congresso Internazionale di Studi Fenici e Punici, Roma, 9-14 novembre 1987, III. Roma: 1211-1214.

— y RUIZ FERNÁNDEZ, J.A. (1987): "Excavaciones de urgencia en El Puerto de Santa María, Cádiz", Revista de Arqueología, 74: 5-12.

RUIZ MATA, D. (1987): "La formación de la cultura turdetana en la Bahía de Cádiz a través del Castillo de Doña Blanca" Iberos. Actas de las I Jornadas sobre el Mundo Ibérico. Jaén, 1985. Jaén: 299-314. (1999): "Visión actual de la fundación de Gadir en la Bahía gaditana. El Castillo de Doña Blanca en el Puerto de Santa María y la ciudad de Cádiz. Contrastación textual y arqueológica", Revista de Historia de El Puerto 21: 11-88.

- y PÉREZ, C.J. (1995): El poblado fenicio del Castillo de Doña Blanca (El Puerto de Santa María, Cádiz) (Biblioteca de Temas Portuenses 5). El Puerto de Santa María, Cádiz.

SANMARTÍ-GREGO, E. (1978a): La cerámica campaniense de Emporion y Rhode. Barcelona, Diputación Provincial de Barcelona.

- (1978b): "L'atelier des patères à trois palmettes radiales et quelques productions connexes", Journées d'etudes de Montpellier sur la céramique campanienne (Archéologie en Languedoc 1): 21-36.

- , CASTANYER I MASOLIVER, P., TREMOLEDA I TRILLA, J. y BARBERA Y FARRAS, J. (1986):

"Las estructuras griegas de los siglos V y IV a. J.-C., halladas en el sector sur de la Neápolis de Ampurias (campaña de excavaciones del año 1986)" Cuadernos de Prehistoria y Arqueología Castellonense 12: 141-184.

SOLIER, Y. (1969): "Note sur les potiers pseudo-campaniens Nikias et Iôn", Revue Archéologique de Narbonnaise 2: 29-48.

- y SANMARTÍ, E. (1978): "Note sur l'atelier pseudo-campanien des rosettes nominales" Journées d'études de Montpellier sur la céramique campanienne (Archéologie en Languedoc 1): 37-42.

SOTO JIMÉNEZ Y ARANAZ, L. (1988): "La Salduba de la Bética (II)", Jábega 59: 3-11.

SPARKES, B.A. y TALCOTT, L. (1970): Black and Plain Pottery of the 6th, 5th and 4th Centuries B.C. (The Athenian Agora XII) Princeton.

TARRADELL, M. (1960): Marruecos púnico. Tetuán.

THUILLIER, J.-P. (1982): “Les sondages dans le secteur nord-est de l'îlot C", Byrsa II. Rapports préliminaires sur les fouilles 1977-1978. Niveaux et vestiges puniques de la mission archéologique française à Carthague (Collection de l'École Française de Rome 41): 249-260.

TORAYA GONZÁLEZ, B., TORRES QUIRÓS, J., LAGÓSTENA BARRIOS, L. y PRIETO REINA, O. (e.p.): "Los inicios de la producción anfórica en la Bahía gaditana en época republicana: La intervención de urgencia en Avda. Pery Junquera (San Fernando, Cádiz)", Congreso Internacional Ex Baetica Amphorae. Conservas, aceite y vino de la Bética en el Imperio Romano. (Sevilla-Écija, diciembre 1998).

VENTURA MARTÍNEZ, J.J. (1990): La Cerámica Campaniense en Andalucía Occidental. IV. Tesis Doctoral inédita. Universidad de Sevilla. 

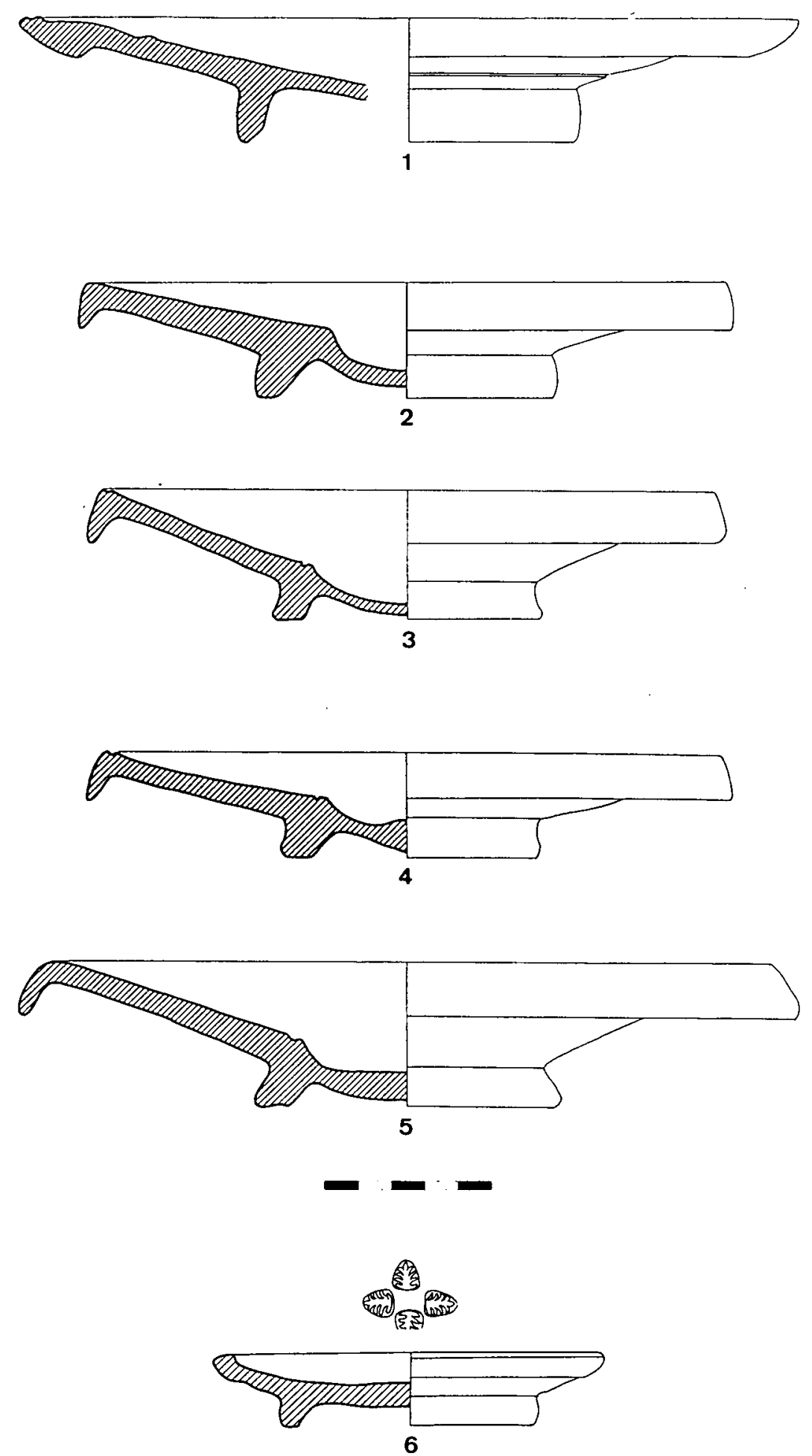

Fig. 1: FORMAS DE LA VAJILLA. I. PLATOS. 1: Plato de borde moldurado. 2-5: Platos de pescado (L-23). 6: "Rolled Rim Plate". 

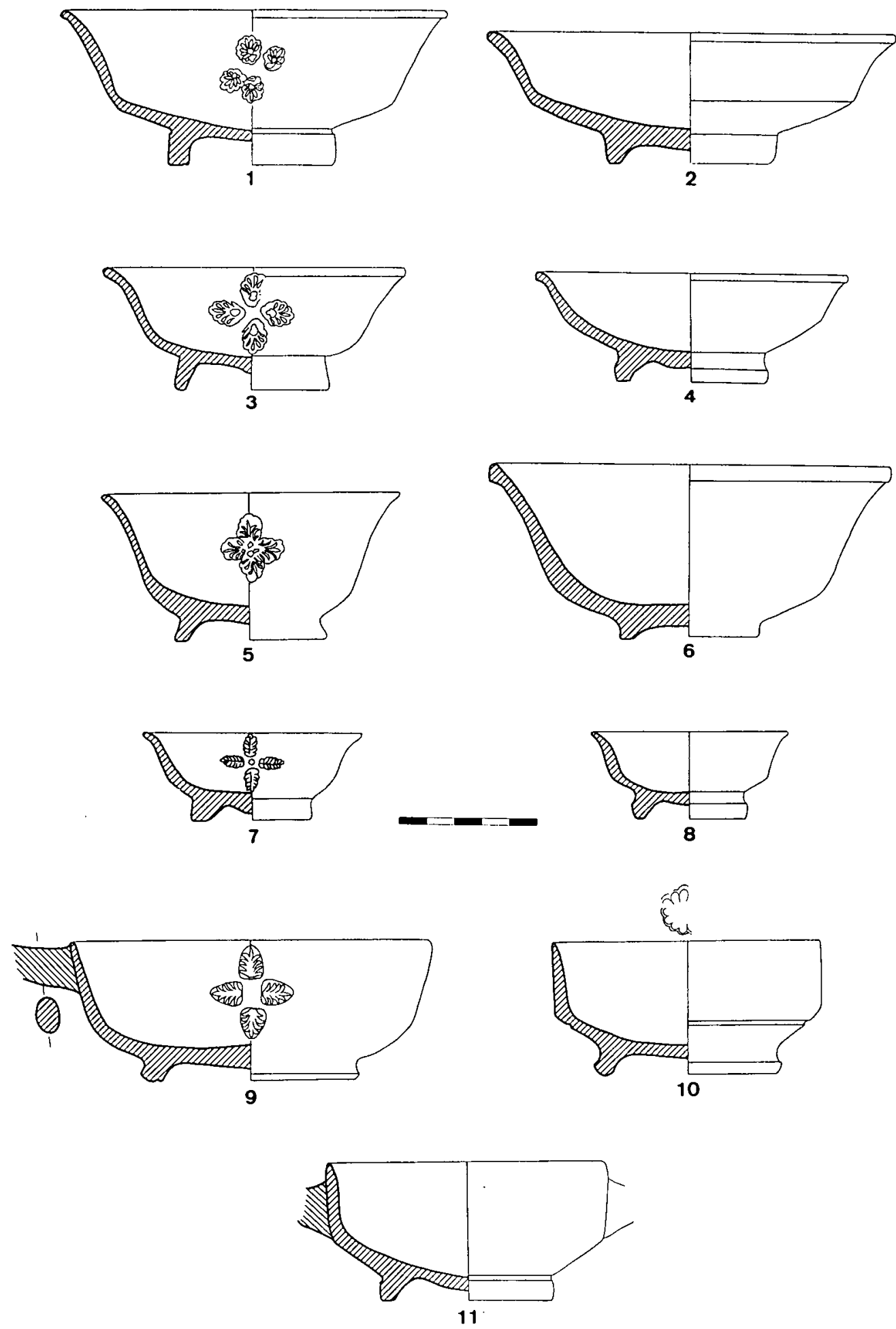

Fig. 2: FORMAS DE LA VAJILLA. II. VASOS PARA BEBER. 1-8: Copas (L-28 y L-29). 9-11: Bolsales. 

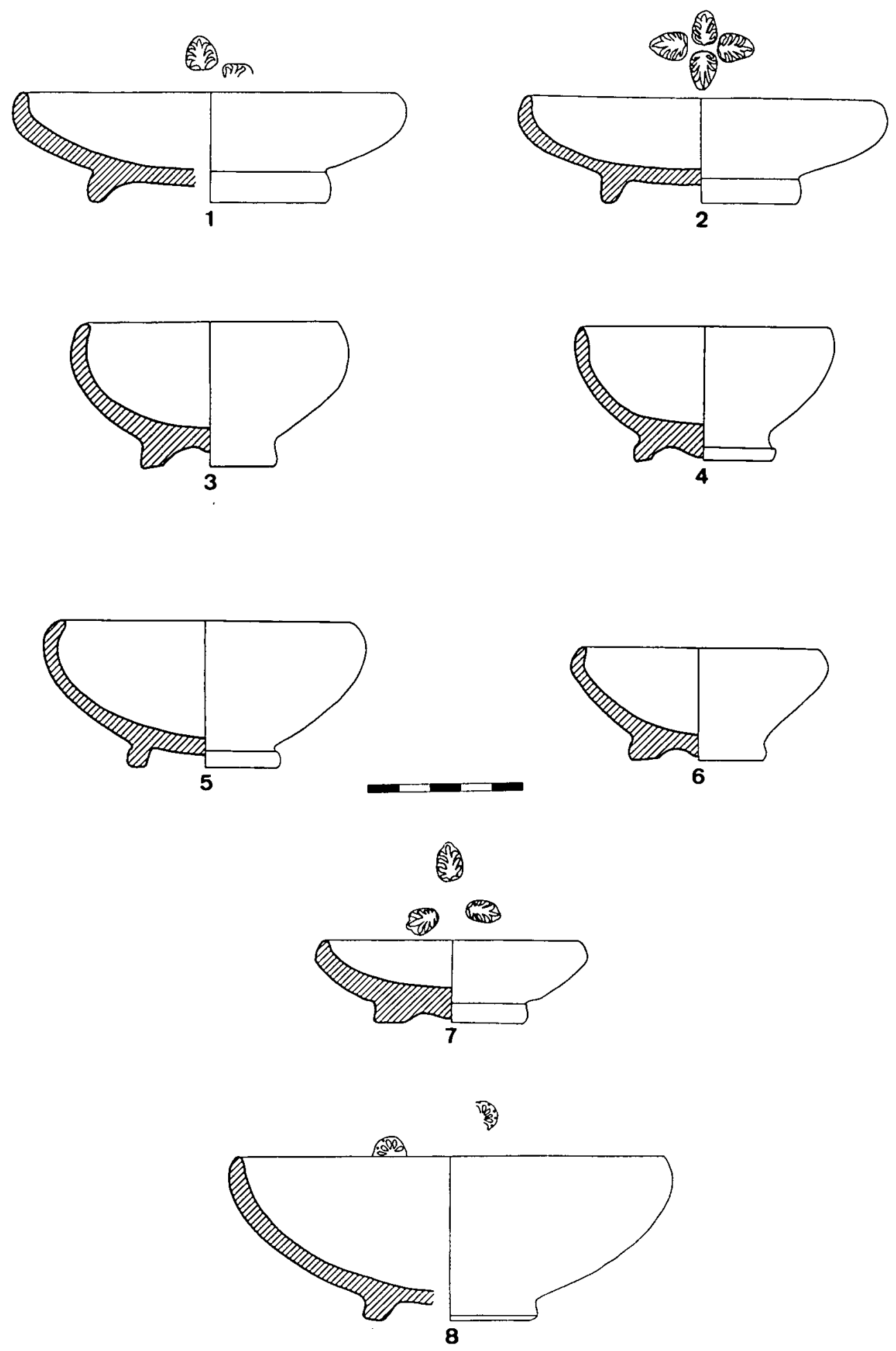

Fig. 3: FORMAS DE LA VAJILLA. III. CUENCOS. 1-2: Formas derivadas de los "Incurving Rim Bowls" áticos. 3-4: Cuencos derivados de los L-24 o los "Saltcellars". 5: Forma L-26. 6: Cuenco L-34. 7: Cuenco de la forma L-21/25 B. 8: L-27. 

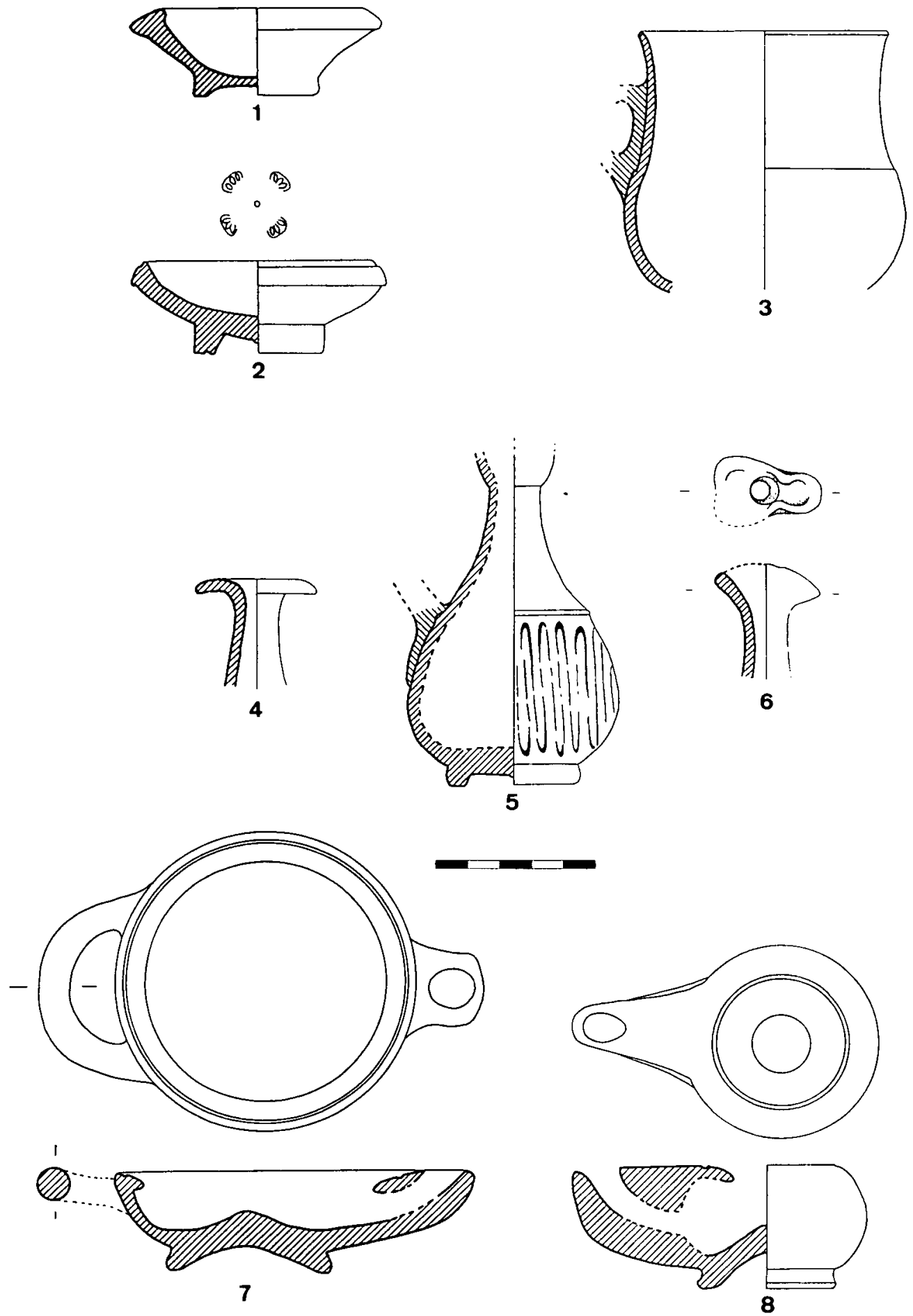

Fig. 4: FORMAS DE LA VAJILLA. IV. OTRAS FORMAS. 1-2: Pequeños cuencos. 3: Vaso o cubilete. 4-6: Ungüentarios. 7-8: Lucernas. 

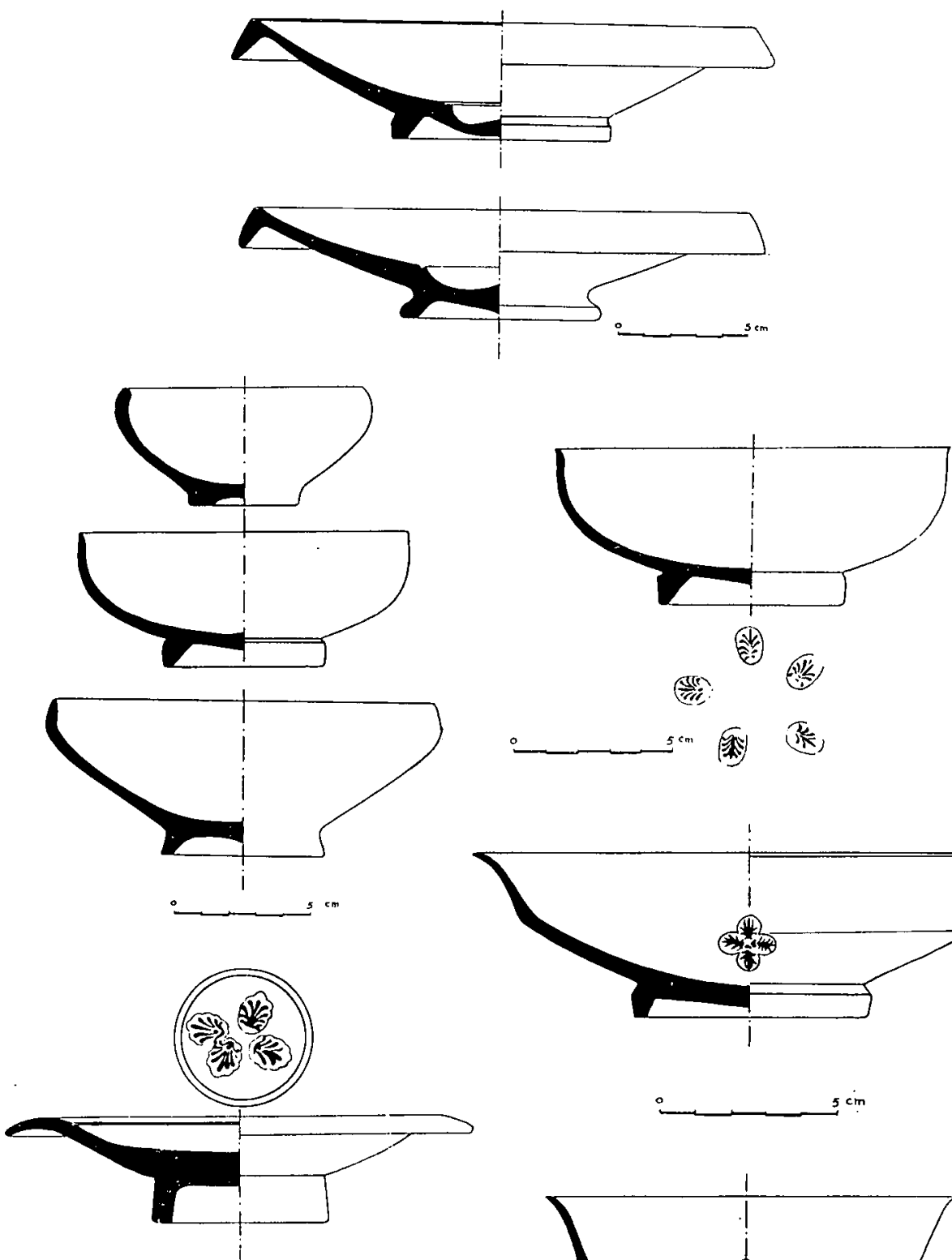

的

留

scm 舆
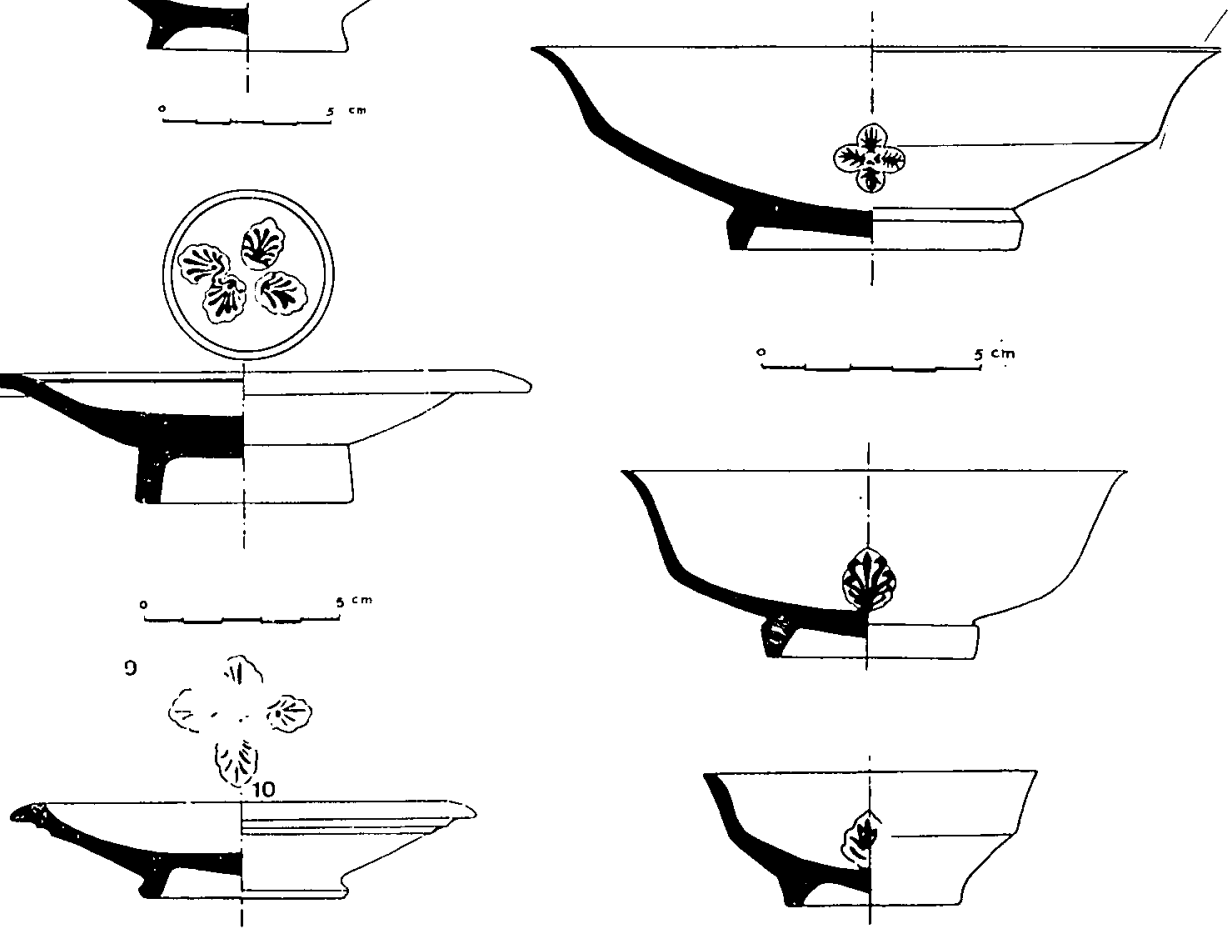

Fig. 5: FORMAS DOCUMENTADAS EN EL YACIMIENTO DE KUASS (ARCILA, MARRUECOS). Según Ponsich 1969. 

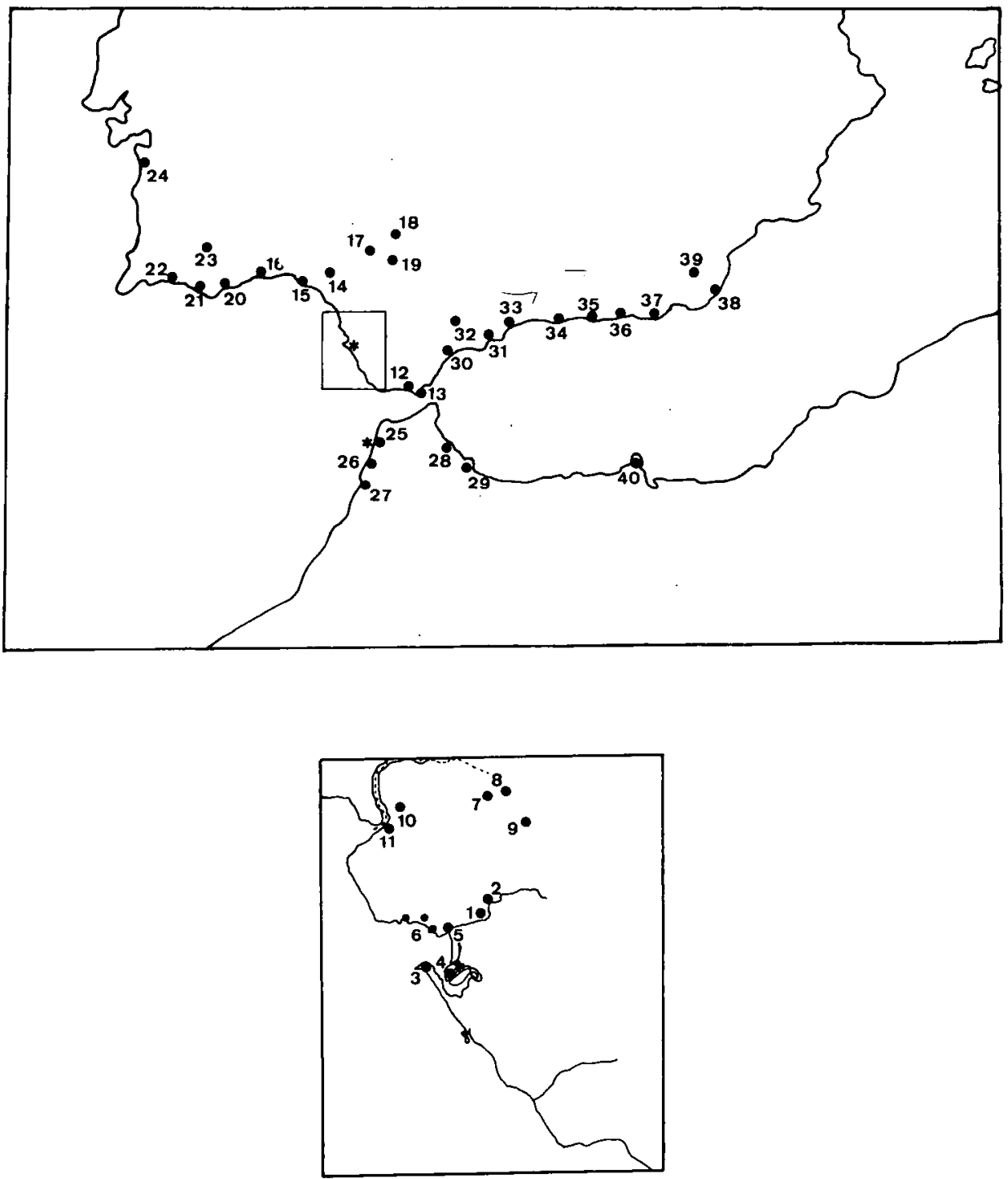

Fig. 6: DISTRIBUCIÓN DE LA VAJILLA TIPO “KUASS" EN EL ÁREA DEL ESTRECHO Y BAHÍA DECÁDIZ. 1: Castillo de Doña Blanca (El Puerto de Santa María, Cádiz). 2: Las Cumbres (El Puerto de Santa María, Cádiz). 3: Casco urbano de Cádiz. 4: Hornos de Torre Alta y Pery Junquera (San Fernando, Cádiz). 5: Casco urbano de El Puerto de Santa María (Cádiz). 6: Factorías de salazones del litoral de Rota y El Puerto de Santa María (Cádiz). 7: Necrópolis de Mesas de Asta (Jerez de la Frontera, Cádiz). 8: Poblado de Mesas de Asta (Jerez de la Frontera, Cádiz). 9: Cerro Naranja (Jerez de la Frontera, Cádiz). 10: Ébora (Sanlúcar de Barrameda, Cádiz). 11: La Algaida (Sanlúcar de Barrameda, Cádiz). 12: Carteia (San Roque, Cádiz). 13: Gorham's Cave (Gibraltar, Cádiz). 14: Niebla (Huelva). 15: Cabezos de Huelva. 16: La Tiñosa (Lepe, Huelva). 17: Itálica (Santiponce, Sevilla). 18: Cerro Macareno (La Rinconada, Sevilla). 19: Casco urbano de Sevilla. 20: Castro Marim (Portugal). 21: Faro (Portugal). 22: Cerro da Rocha Branca (Silves, Portugal). 23: Mértola (Portugal). 24: Miróbriga (Santiago do Cacém, Portugal). 25: Kuass (Arcila, Marruecos). 26: Zilii (Marruecos). 27: Lixus (Larache, Marruecos). 28: Sidi Abdselam del Behar (Marruecos). 29: Kudia Tebmain (Emsá, Marruecos). 30: El Torreón (Estepona, Málaga). 31: Malaka (Casco urbano de Málaga). 32: Cerro de la Tortuga (Antequera, Málaga). 33: Morro de Mezquitilla (Algarrobo, Málaga). 34: Almuñécar (Granada). 35: Salobreña (Granada). 36: Cerro de Montecristo (Adra, Almería). 37: Ciavieja (El Ejido, Almería). 38: Villaricos (Cuevas de Almanzora, Almería). 39: Cabecico de Parra (Cuevas de Almanzora, Almería). 40: Russadir (Melilla).

Marcado con un asterisco $(*)$ la situación de los alfares. 

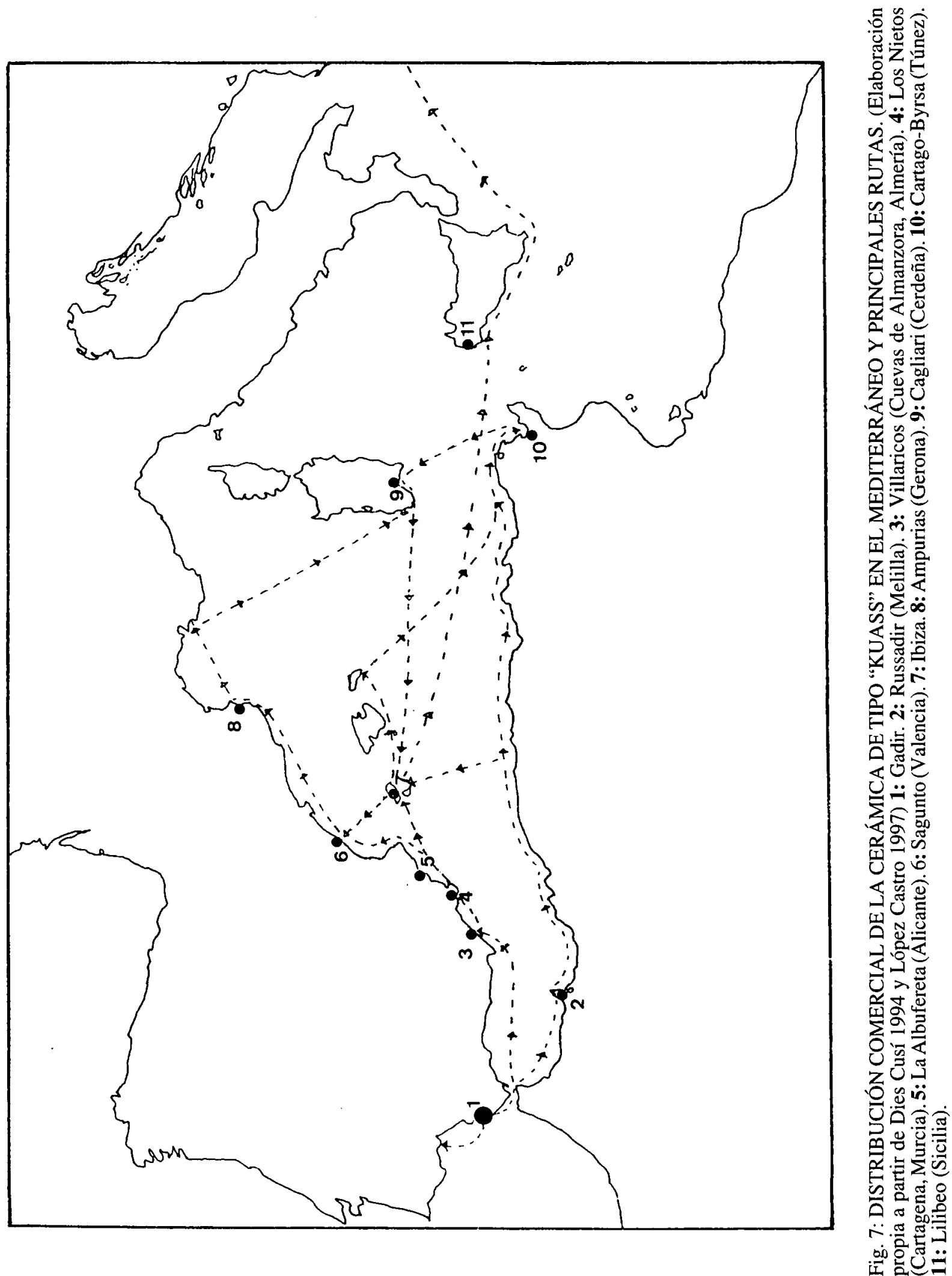